
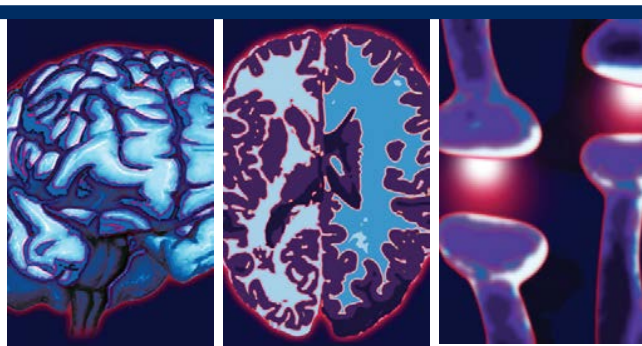

\title{
A Systematic Review on Factitious Disorders: Psychopathology and Diagnostic Classification
}

\author{
Ivano Caselli, Nicola Poloni, Francesca Ceccon, Marta Ielmini, Beatrice Merlo, Camilla Callegari ${ }^{\dagger}$
}

\begin{abstract}
Factitious disorder (FD) is a psychiatric disorder in which sufferers intentionally fabricate physical or psychological symptoms in order to assume the role of the patient, without any obvious gain. The clinical and demographic profile of patients with FD has not been sufficiently clarified. The aims of this study are: to outline a demographic and clinical profile of a large sample of patients with FD, to highlight the psychopathological correlates and to study the evolution of position of FD in the DSM. A systematic search for all case reports and case series of adult patients in the databases MEDLINE, Scopus and PsycINFO was conducted. 1636 records were obtained based on key search terms, after exclusion of duplicate records. 577 articles were identified as potentially eligible for the study, of which 314 studies were retrieved for full-text review. These studies included 514 cases. Variables extracted included age, gender, reported occupation, comorbid psychopathology, clinical presentation and factors leading to the diagnosis of FD. $64.5 \%$ of patients in the sample were females. Mean age at presentation was 33.5 y.o. A healthcare profession was reported most frequently $(n=113)$. Patients were most likely to present in psychiatry, neurology, emergency and internal medicine departments. Statistical analysis has highlighted significant correlations between factitious disorders and depressive disorders and borderline personality disorder (BPD) and a significant effect of BPD and abuses in childhood on substance abuse. The survey of socio-demographic profile of the sample has highlighted some important points for early diagnosis and early psychiatric treatment. The research also allows deepening the psychopathological correlates of the disorder. The study showed that patients did not meet DSM- 5 diagnostic criteria in the $11.3 \%$ of cases.
\end{abstract}

\section{Keywords}

Factitious disorder, Munchausen syndrome, Fabricated illness, Medically unexplained symptoms

\begin{abstract}
Introduction
Factitious disorder (FD) is a psychiatric disorder in which sufferers intentionally fabricate physical or psychological symptoms in order to assume the role of the patient, without any obvious gain [1]. (DSM-5 2013). Patients with FD often gain hospital admission and undergo invasive procedures and surgeries exposing themselves to a considerable risk of iatrogenic harm.
\end{abstract}

It is possible to identify some predisposing factors for the development of FD. The most significant factors include other mental disorders, general medical conditions that require treatment and hospitalization, especially in childhood or adolescence, deprivation stories (losses, family breakdowns), emotional and physical abuses in childhood [2].

The exact prevalence of the disorder is currently unknown but it has been estimated between 
$0.6 \%$ and $3 \%$ of referrals from general medicine to psychiatryand between $0.02 \%$ and $0.9 \%$ of cases reviewed in specialist clinics [3].

Factitious disorders appeared in the Diagnostic and Statistical Manual of Mental Diseases from the third edition (1980). According to DSMIII-R (1986), factitious disorders should be distinguished from malingering in which fabrication is motivated by an external reward.

In DSM-IV-TR (2000), FD represents an autonomous diagnostic category. Three subtypes of distinct fictitious disorder are distinguished by predominant symptoms.

With Predominant Psychic Signs and Symptoms

With Predominant Physical Signs and Symptoms

Combined Psychic and Physical Signs and Symptoms.

In DSM-5 FD are part of the largest section of Somatic Symptom and Related Disorders (Table 1). All the disorders of this chapter have in common the relevance of somatic symptoms associated with significant discomfort and impairment. This diagnostic formulation is more useful to general practitioners and non-psychiatric specialists in the field of general medicine and in other clinical areas where individuals who present disorders with significant somatic symptoms are more common than in mental healthcare services. As other somatic symptom disorders, factitious disorder is characterized by persistent problems related to the perception of illness and identity.

Early detection of factitious disorder is very important to limit harm to patients and early management of FD may facilitate improved outcomes for patients with the disorder.

However, the clinical and demographic profile of patients with FD has not been sufficiently clarified $[4,5]$. Recommendations and guidelines have not been supported by broad evidence on how FD is diagnosed by clinicians or how methods for early detecting FD may vary among medical specialties.

Studies on FD demonstrate the huge impact of unnecessary investigations, treatments and hospital admission on the healthcare system. Early detection of FD is in order to limit wastage of healthcare resources and harm to patients $[6,7]$.

Articles on FD are mostly case reports and reviews. Only a limited number of studies have been published in the literature and those published to date have been limited to a small number of cases.

Thus, the aim of this study is to draft a comprehensive systematic review of all cases of factitious disorders published in the professional literature.

Factitious patients are difficult to detect and they have a heavy impact on the healthcare services and National Health Service. The need for improving and speeding up the diagnostic approach and consequently therapeutic treatments is felt. Thus, it is useful to carry out a literature review to characterize the profile of patients with FD. Purposely, the endpoints are:

to outline a demographic and clinical profile of a large sample of patients with factitious disorder;

to highlight the psychopathological correlates;

to study the evolution of position of FD in the Diagnostic and Statistical Manual of Mental Disorders

\section{Method}

A systematic review of all case report and case series of adult patients which fulfilled DSM-5 diagnostic criteria was conducted. The research involved cases diagnosed according to DSM-III, DSM-IV or ICD-10 criteria. A broad keyword search of the professional literature published in English from January 1950 until November 2016 was conducted by two couple of raters. The databases MEDLINE, Scopus and PsycINFO were searched using the MeSH terms factitious and munchausen. The terms artefacta, fabricated illness and medically unexplained symptoms were included. Exclusion criteria are the following:

cases by proxy

aged $<18$ y.o.

articles not in English

The PRISMA (Preferred Reporting Items for Systematic Review and Meta-Analyses) flow chart of the search is reported. A total of 1636 records were returned based on key search terms, after exclusion of duplicate records. 577 articles were identified as potentially eligible for the study based on title and abstract, of which 314 studies were retrieved for full-text review. These studies included 514 cases. Single cases have been extracted from $74.1 \%$ of the studies, while $25.9 \%$ of the selected articles contained multiple cases (Figure 1). 
Table 1: FD Diagnostic criteria in DSM-IV-TR vs DSM-5.

\begin{tabular}{|c|c|}
\hline Factitious Disorder (DSM-IV-TR) & Somatic Symptom Disorder (DSM-5) \\
\hline $\begin{array}{l}\text { A. Intentional production or feigning of physical or psychological signs or } \\
\text { symptoms. }\end{array}$ & $\begin{array}{l}\text { A. One or more somatic symptoms that are distressing or result in } \\
\text { significant disruption of daily life. }\end{array}$ \\
\hline B. The motivation for the behavior is to assume the sick role. & $\begin{array}{l}\text { B. Excessive thoughts, feelings, behaviors related to the somatic symptoms } \\
\text { or associated health concerns as manifested by at least one of the following: } \\
\text { 1. Disproportionate and persistent thoughts about the seriousness of one's } \\
\text { symptoms. } \\
\text { 2. Persistently high level of anxiety about health or symptoms. } \\
\text { 3. Excessive time and energy devoted to these symptoms or health } \\
\text { concerns. }\end{array}$ \\
\hline $\begin{array}{l}\text { C. External incentives for the behavior (such as economic gain, avoiding } \\
\text { legal responsibility, or improving physical well-being, as in Malingering) are } \\
\text { absent. }\end{array}$ & $\begin{array}{l}\text { C. Although any somatic symptom may not be continuously present, the } \\
\text { state of being symptomatic is persistent (typically more than } 6 \text { months). }\end{array}$ \\
\hline $\begin{array}{l}\text { Code based on type: } \\
\text { 300.16 With Predominantly Psychological Signs and Symptoms: if } \\
\text { psychological signs and symptoms predominate in the clinical presentation } \\
300.19 \text { With Predominantly Physical Signs and Symptoms: if physical signs } \\
\text { and symptoms predominate in the clinical presentation } \\
300.19 \text { With Combined Psychological and Physical Signs and Symptoms: if } \\
\text { both psychological and physical signs and symptoms are present but neither } \\
\text { predominates in the clinical presentation }\end{array}$ & $\begin{array}{l}\text { Specify if: } \\
\text { With predominant pain (previously pain disorder): This specifier is for } \\
\text { individuals whose somatic symptoms predominantly involve pain. } \\
\text { Specify if: } \\
\text { Persistent: a persistent course is characterized by severe symptoms, marked } \\
\text { impairment and long duration (more than } 6 \text { months). } \\
\text { Specify current severity: } \\
\text { Mild: only one of the symptoms specified in Criterion B is fulfilled. } \\
\text { Moderate: two or more of the symptoms specified in Criterion B are fulfilled. } \\
\text { Severe: two or more of the symptoms specified in Criterion B are fulfilled, } \\
\text { plus there are multiple somatic symptoms (or one severe somatic } \\
\text { symptom). }\end{array}$ \\
\hline
\end{tabular}

The following quantitative and qualitative variables were obtained: age, gender, marital status, race and ethnicity, reported occupation, psychopathology, medical diseases, clinical presentation, multiple surgeries, abuse in childhood, substance abuse, experience of illness or long-lasting hospitalization, traumatic experiences, conflicting relationships, premature familiar bereavements, grudge towards the medical profession, use of para-medical facilities, suicidal behavior, cause of death, psychiatric counseling.

Factors leading to the diagnosis of FD were extracted using a checklist adapted from two surveys of clinical information that might raise the suspicion of factitious disorder [5,8]. Starting from the review of Yates and Steel, these items were considered: past healthcare service use, atypical presentation, exclusion of organic and/ or psychiatric causes, evidence of fabrication, patient behavior, treatment failure, recurrent disease $[3,5]$.

The past healthcare services use consists in a history of extensive use of medical services, history of peregrination between healthcare services and multiple medical examinations request.
The atypical presentation includes the manifestation of symptoms when the patient is not under observation, the course of illness is impossible or highly improbable or does not follow the natural history of the presumed diagnosis.

The exclusion of organic causes carries out from clinical examination and execution of instrumental diagnostic and laboratory investigations. The evidence of fabrication occurs through search, surveillance or direct admission by the patient.

The patient's behavior includes unusual medical knowledge or the use of medical and scientific terms, the extreme eagerness for medical procedures, including invasive ones, attitude of revenge towards health workers, poor adherence to the proposed treatments, pseudologia fantastica and opposition to the psychiatric consultation instead of medical or surgical procedures. The failure of treatments includes numerous disease relapses and the appearance of new symptoms in conjunction to the treatment or worsening of the medical condition.

In order to collect the elements of the database for the statistical analysis, missing or doubt socio- 
Research Camilla Callegari

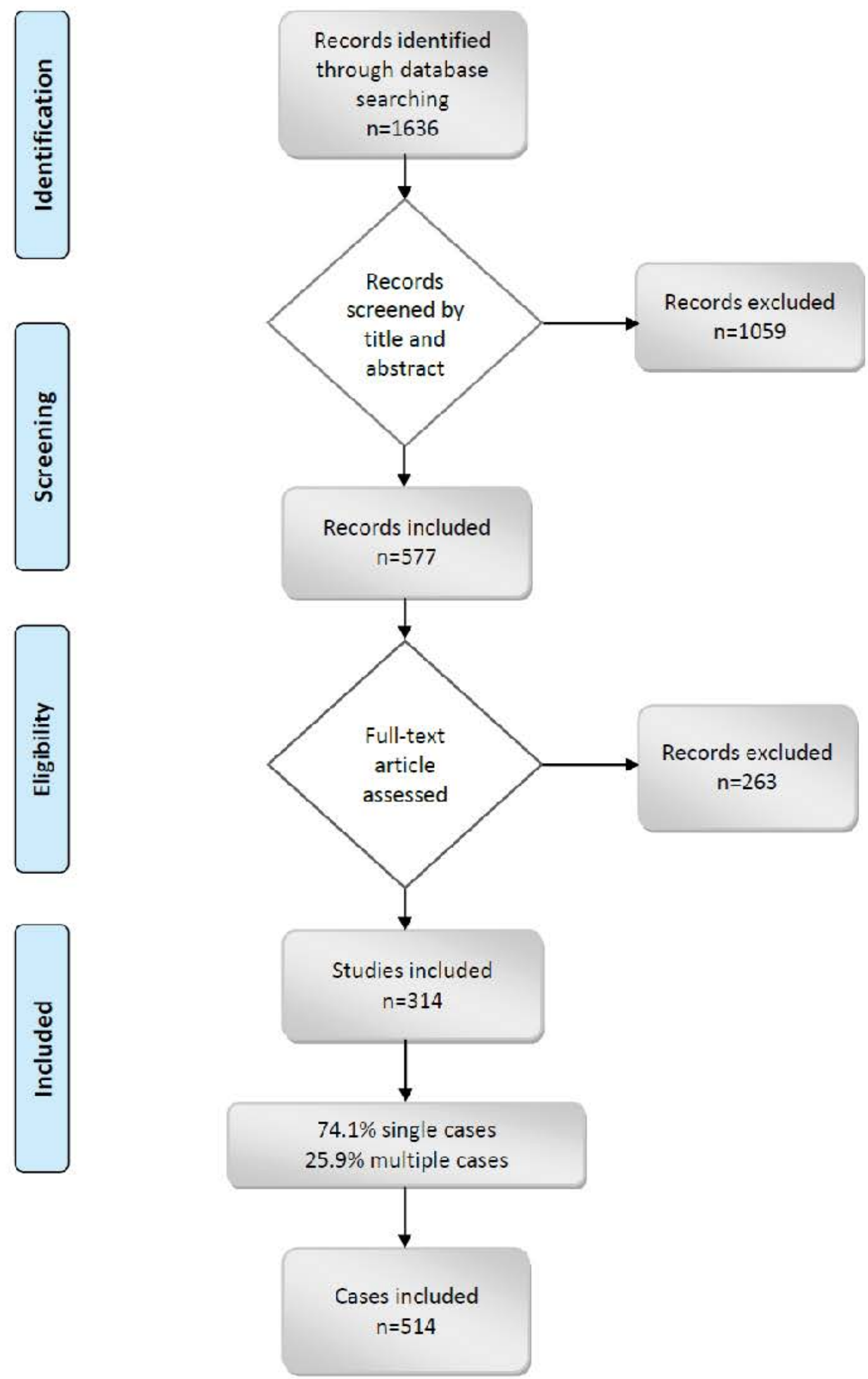

Figure 1: Prisma flow chart. 
demographic medical and clinical data have been considered as "unknown". Presentation of FD was extracted considering the one which was the object of clinical and diagnostic investigations into the studies.

IBM SPSS 22 was used to calculate descriptive statistics. Statistical significance was investigated using a Pearson test and linear regression models.

\section{Results}

As showed in Table 2 the sample is composed by $34.2 \%$ males and $65.4 \%$ females. In $0.4 \%$ of cases it is not possible to establish the gender of subjects from the anamnestic data reported. From the data analysis there is a clear prevalence of the diagnosis of FD in female gender. The average age of general population is 33.5 y.o. (DS 10.6), and the average age of women is 32.8 y.o. (DS 10.9), while male is 35 y.o. (DS 9.7).

As far as concerned the employment, healthcare workers account for $22 \%$ of the sample $(n=113)$, while $18.3 \%(n=94)$ are represented by other professions. In $59.7 \% \quad(\mathrm{n}=307)$ the data is unavailable or unreliable. Despite the unavailable data, in the group in which the employment is available $(n=207)$ the figure of the nurse is the most significant with the $23.7 \%$. A rate of unemployment of $11.1 \%$ was found.

For a large number of patients the civil status is not available $(63.1 \%$ of women and $58.6 \%$ of men); where this datum is available a prevalence of married people both in men (17.6\%) and women $(19.6 \%)$ emerged.

$28.4 \%(n=146)$ of patients presents a medical comorbidity and $40.1 \%(\mathrm{n}=206)$ shows one or more psychiatric disorders. The most frequently psychiatric pathologies associated with FD are personality disorders in $43.1 \%$ and depressive disorders in $37.7 \%$. The presence of psychiatric comorbidity is excluded in $39.5 \%(n=203)$.

In the family history the presence of psychiatric diseases and related disorders is positive in $4.9 \%$ $(n=25)$ of patients. In the most cases $(96 \%)$ the diagnosis is substance abuse.

With regard to the medical specialties to which factitious patients are concerned, there are minimal differences between the gender of the sample: for men the most represented specialty is psychiatry $(31.5 \%)$, followed by emergency department (16.7\%) and internal medicine $(8 \%)$. For women, the psychiatric ward appears in $22.1 \%$ of cases, followed by internal medicine (7.5\%) and gynecology (6.5\%) (Table 3).

A further psychopathological aspect useful to analyze is the subdivision in presentation with internal and external signs/symptoms. Depending on the polarity of the factitious behavior, localization of self-harm may be superficial (e.g. skin ulcers) or internal (e.g. anemia, internal organ damage). The sample shows a prevalence of internal signs/symptoms $(87.4 \%)$. The $35 \%$ of patients have a positive history for multiple surgical procedures.

As far as concerned the prevalence of all stressful events in correlation with FD the following outcomes emerged: $20.2 \%$ of the patients show stressful or traumatic events, $14.6 \%$ have physical or sexual abuses or neglect in childhood, $16.9 \%$ show substance abuse, $10.7 \%$ have conflicting and/or unstable interpersonal relationships and $7.2 \%$ reveal premature familiar bereavements. The $13.4 \%$ of patients presents a suicidal behavior.

\begin{tabular}{|c|c|c|c|}
\hline & & $\mathbf{N}$ & $\%$ \\
\hline \multirow{2}{*}{ Gender } & Male & 176 & 34.2 \\
\hline & Female & 336 & 65.4 \\
\hline \multirow{3}{*}{ Marital status } & Unmarried & 62 & 30.4 \\
\hline & Married & 97 & 47.5 \\
\hline & Separated/Divorced/Widowed & 45 & 22.0 \\
\hline \multirow{6}{*}{ Age } & Total mean & \multicolumn{2}{|l|}{33.5 y.о. } \\
\hline & Male & \multicolumn{2}{|l|}{35 у.о. } \\
\hline & Female & \multicolumn{2}{|l|}{32.8 у.о. } \\
\hline & Total range & \multicolumn{2}{|l|}{$18-73$ у.о. } \\
\hline & Male range & \multicolumn{2}{|l|}{ 19-67 y.o. } \\
\hline & Female range & \multicolumn{2}{|l|}{ 18-73 у.о. } \\
\hline Comorbid psychopatology & & 239 & 46.5 \\
\hline \multirow{2}{*}{ Occupation } & Healthcare profession & 113 & 22.0 \\
\hline & Others & 94 & 18.3 \\
\hline
\end{tabular}


Research Camilla Callegari

\begin{tabular}{|c|c|c|c|}
\hline & $\mathrm{N}$ & $\%$ & Clinical presentation \\
\hline Neurology and Neurosurgery & 51 & $9.9 \%$ & $\begin{array}{l}\text { Undefined neurological syndrome }(n=9) \text {; Paralysis }(N=12) \text {; Epilepsy }(n=12) \text {; Paresis }(n=1) \text {; } \\
\text { Multiple sclerosis }(n=3) \text {; Dystonia/Apraxia }(n=3) \text {; Dysarthria }(n=1) ; \text { Precoma }(n=1) \text {; Post-polio } \\
\text { syndrome }(n=2) ; \text { Neuropathy }(n=2) \text {; Migraine headache }(n=1) \text {; Vascular dementia }(n=1) \text {; } \\
\text { Amnesia }(n=2) ; \text { Subarachnoid heamorrhage }(n=1) \text {. }\end{array}$ \\
\hline Psychiatry & 95 & $18.5 \%$ & $\begin{array}{l}\text { Munchausen syndrome ( } n=31) \text {; PTSD ( } n=15) \text {; Depression }(n=8) \text {; Schizophrenia }(n=3) \text {; Suicide } \\
(n=1) \text {; Ermaphroditism ( } n=1) \text {; Psychic symptoms }(n=36)\end{array}$ \\
\hline Rheumatology e Allergology & 23 & $4.5 \%$ & $\begin{array}{l}\text { Osteoarticularpain }(n=11) \text {; Arthritis }(n=5) \text {; Allergy }(n=2) \text {; Raynaud's phenomenon }(n=2) \text {; SLE } \\
(n=1) \text {; Collagenopathy }(n=1) \text {; Granulomatous disease }(n=1)\end{array}$ \\
\hline $\begin{array}{l}\text { Infectious and Tropical } \\
\text { diseases }\end{array}$ & 44 & $8.6 \%$ & $\begin{array}{l}\text { AIDS/HIV ( } n=19) ; \text { Infection ( } n=16) ; \text { FUO }(n=6) \text {; Endocarditis }(n=1) \text {; Parasitosis }(n=1) \text {; Tropical } \\
\text { disease }(n=1)\end{array}$ \\
\hline Respiratory department & 13 & $2.5 \%$ & $\begin{array}{l}\text { Respiratory tract hemorrhage }(n=6) \text {; ARDS }(n=3) \text {; Asthma }(n=2) \text {; Pulmonary emphysema } \\
(n=1) \text {; Pulmonary fibrosis }(n=1)\end{array}$ \\
\hline Endocrinology & 29 & $5.6 \%$ & $\begin{array}{l}\text { Cushing syndrome }(n=11) \text {; Hypoglycemia }(n=11) \text {; Feocromocytoma }(n=3) \text {; Hyperthyroidism } \\
(n=2) \text {; Hypercortisoluria }(n=1) \text {; Chetoacidosis }(n=1)\end{array}$ \\
\hline Nephrology and Urology & 18 & $3.5 \%$ & $\begin{array}{l}\text { Urinary calculi }(n=6) \text {; Urinary haemorrhage }(n=6) \text {; GN }(n=2) \text {; Urinary retention }(n=1) \text {; UTIs } \\
(n=1) \text {; Proteinuria }(n=1) \text {; Fournier gangrene }(n=1)\end{array}$ \\
\hline Dermatology & 44 & $8.6 \%$ & $\begin{array}{l}\text { Skin ulcer }(n=10) \text {; Panniculitis }(n=8) \text {; Skin lesion }(n=7) \text {; Subcutaneous abscess }(n=6) \text {; } \\
\text { Lower body edema }(n=4) \text {; Dermatitis }(n=4) \text {; Cyanosis }(n=2) \text {; Subcutaneous masses }(n=1) \text {; } \\
\text { Subcutaneous haemorrhage }(n=1) \text {; Fistula }(n=1)\end{array}$ \\
\hline Cardiology and Angiology & 20 & $3.9 \%$ & $\begin{array}{l}\text { MI }(n=5) \text {; Chest pain }(n=4) \text {; Lipothymia/Syncope }(n=3) \text {; Hypertension }(n=3) \text {; DVT }(n=2) \text {; } \\
\text { Arrhythmia }(n=1) \text {; Hypovolemia }(n=1) \text {; Cardio-circolatory failure }(n=1)\end{array}$ \\
\hline Gynecology andMidwifery & 9 & $1.8 \%$ & $\begin{array}{l}\text { Vaginal bleeding }(n=4) \text {; Premature birth }(n=2) \text {; Complicated pregnancy }(n=1) \text {; Hyperemesis } \\
\text { gravidarum }(n=1) \text {; Breast pain }(n=1)\end{array}$ \\
\hline Hematology & 22 & $4.3 \%$ & $\begin{array}{l}\text { Anemia }(n=15) \text {; Coagulopathy }(n=3) \text {; Mastocytosis/Thrombocytopenia }(n=2) \text {; } \\
\text { Hypogammaglobulinemia }(n=1) \text {; Haemophilia }(n=1)\end{array}$ \\
\hline Gastroenterology & 23 & $4.5 \%$ & $\begin{array}{l}\text { Abdominal pain }(n=9) \text {; Gastrointestinal haemorrhage }(n=5) \text {; Hyperemesis }(n=3) \text {; Diarrhea } \\
(n=2) \text {; Intestinal occlusion }(n=1) \text {; Acute abdomen }(n=1) ; \operatorname{IBD}(n=1) \text {; Cystic fibrosis }(n=1)\end{array}$ \\
\hline $\begin{array}{l}\text { Otolaryngology and } \\
\text { Ophthalmology }\end{array}$ & 19 & $3.7 \%$ & $\begin{array}{l}\text { Blindness }(n=5) \text {; ORL symptoms }(n=3) \text {; Nasal haemorrhage }(n=2) \text {; Corneal injury }(n=2) \text {; } \\
\text { Ludwig's angina }(n=1) \text {; Deaf-dumbness }(n=1) \text {; Stomatitis }(n=1) \text {; Usher syndrome }(n=1) \text {; Otitis } \\
(n=1) \text {; Endophthalmitis }(n=1) \text {; Ear haemorrhage }(n=1)\end{array}$ \\
\hline $\begin{array}{l}\text { Traumatology and Emergency } \\
\text { room }\end{array}$ & 60 & $11.7 \%$ & $\begin{array}{l}\text { Wounds }(n=16) ; \text { Trauma/Polytrauma }(n=11) \text {; Haemorrhage NOS }(n=9) \text {; Pneumothorax }(n=4) \text {; } \\
\text { Burn }(n=3) \text {; Subcutaneous emphysema }(n=3) \text {; Decompression sickness }(n=3) \text {; Angioedema } \\
(n=3) \text {; Poisoning }(n=2) \text {; Aortic dissection }(n=2) \text {; Electrolyticdisorders }(n=2) \text {; Osteonecrosis } \\
(n=1) \text {; Anaphylaxis }(n=1)\end{array}$ \\
\hline Oncology & 10 & $1.9 \%$ & Cancer NOS ( $n=8)$; Breast cancer $(n=2)$ \\
\hline Genetics & 1 & $0.2 \%$ & Disease NOS $(n=1)$ \\
\hline Intensive and Palliative care & 14 & $2.7 \%$ & $\begin{array}{l}\text { Chronic pain }(n=6) \text {; Post-surgical pain }(n=5) \text {; Complications of anesthesia }(n=2) \text {; Neuropatic } \\
\text { pain }(n=1)\end{array}$ \\
\hline $\begin{array}{l}\text { Undefined } \\
\text { physical symptoms }\end{array}$ & 14 & $2.7 \%$ & \\
\hline $\begin{array}{l}\text { Undefined } \\
\text { symptoms }\end{array}$ & 5 & $1.0 \%$ & \\
\hline \multicolumn{4}{|l|}{ Legend: } \\
\hline \multicolumn{4}{|l|}{$F U O=$ fever of unknown origin } \\
\hline \multicolumn{4}{|c|}{ ARDS= acute respiratory distress syndrome } \\
\hline \multicolumn{4}{|l|}{$G N=$ glomerulonephritis } \\
\hline \multicolumn{4}{|l|}{ UTIs= urinary tract infections } \\
\hline \multicolumn{4}{|l|}{$\mathrm{MI}=$ myocardial infarction } \\
\hline \multicolumn{4}{|l|}{$\mathrm{DVT}=$ deep vein thrombosis } \\
\hline \multicolumn{4}{|l|}{$\mathrm{IBD}=$ inflammatory bowel disease } \\
\hline \multicolumn{4}{|l|}{ NOS $=$ not otherwise specificated } \\
\hline
\end{tabular}


The $65.8 \%$ of patients got a psychiatric consultation during hospitalization. The remaining $34.2 \%$ of patients refused or did not have the consultation.

Among the factors considered to be relevant to diagnose these disorders, the exclusion of other organic or psychiatric causes is the most represented, observed in the $91.1 \%$ of cases.

An atypical presentation is another key issue $(89.3 \%)$, which implies that the patient's symptoms or the clinical course of the presumed condition are unusual, sometimes associated with incongruous instrumental findings. In some cases it is also possible to observe an exacerbation of the symptoms in the presence of the medical staff or, on the contrary, in the absence of any witnesses.

Another important parameter is patient's unusual behavior $(86.2 \%)$, followed by treatment failure and/or high disease recurrence (83.7\%).

This last point is linked to another parameter that can address such diagnosis, which is the past use of health services that in this study has occurred in $72.6 \%$ of cases.

Evidence of factitious production has only been observed in $38.1 \%$ of cases.

Table 4 shows zero order Pearson correlations between the following variables: depressive disorders, borderline personality disorders, substance abuse, and childhood abuse and illness/hospitalization experiences.

As shown in Table 4, it is possible to identify a statistically significant correlation, in female patients, between drug abuse and borderline personality disorder (BPD) and between drug abuse and depressive disorder, according to Pearson coefficient. There is also a statistically significant correlation between the presence of child abuses and/or neglect in childhood and the diagnosis of depressive disorder and drug abuse.

Among male patients, a statistically significant correlation between drug abuse and the presence of borderline personality disorder is noticed.

As for females, a statistically significant correlation between child abuse and substance abuse is noticed in this group of patients. It is also possible to highlight a correlation between early age abuses and a history of illnesses and/or hospitalization during childhood.

We ran hierarchical multiple linear regression analyses to investigate the associations of substance abuse, set as dependent variable, with a series of predictors. Variables included in the model were BPD traits and depressive symptoms (Model 1), childhood abuse and hospitalization (Model 2). Analyses were run separately for men and women.

According to the evidence of the statistical significance of Pearson's simple correlations, it is possible to insert the variables into a linear multiple regression model (Table 5). Model 1 explained a significant percentage of variance in the dependent variable, which is the substance abuse, for both the female gender (R-frame $=.071, \mathrm{~F}(2)=12.51 ; \mathrm{p}<.001)$ and the male gender (R-frame $=.040, F(2)=3.74 ; \mathrm{p}<.025)$.

According to this model, it is possible to highlight that in females both the diagnosis of depressive disorder and of borderline personality disorder give a significant predisposition to substance abuse $(\mathrm{p}<0.05)$.

In males, the diagnosis of borderline personality disorder has a significant effect on drug abuse, excluding depression scores $(\mathrm{p}<0.05)$.

\section{Table 4: Pearson correlations in male and female sample.}

\begin{tabular}{|c|c|c|c|c|c|}
\hline Female sample $(\mathrm{N}=330)$ & DD & BPD & SA & Childhood Abuse & Illness \\
\hline Depressive disorder (DD) & - & .03 & $.13^{*}$ & $.14^{* *}$ & .06 \\
\hline Borderline Personality Disorder (BPD) & .03 & - & $.24^{* * *}$ & .04 & .00 \\
\hline Substance Abuse (SA) & $.13^{*}$ & $.24^{* * *}$ & - & $.23^{* * *}$ & .10 \\
\hline Childhood abuse & $.14^{* *}$ & .04 & $.23^{* * *}$ & - & .08 \\
\hline IIlness/hospitalization experiences & .06 & .00 & .10 & .08 & - \\
\hline \multicolumn{6}{|l|}{ Male sample $(\mathrm{N}=184)$} \\
\hline Depressive Disorder & - & -.00 & .07 & $.16^{*}$ & .10 \\
\hline Borderline Personality Disorder & -.00 & - & $.18^{*}$ & .09 & .10 \\
\hline Substance Abuse & .07 & $.18^{*}$ & - & $.19^{*}$ & .12 \\
\hline Childhood abuse & $.16^{*}$ & .09 & $.19^{*}$ & - & $.18^{*}$ \\
\hline Illness/Hospitalization experieces & .10 & .02 & .12 & $.18^{*}$ & - \\
\hline \multicolumn{6}{|l|}{${ }^{*} \mathrm{p}<.05 ;{ }^{* *} \mathrm{p}<.01 ;{ }^{* * *} \mathrm{p}<.001$ (two tails) } \\
\hline
\end{tabular}




\begin{tabular}{|c|c|c|c|c|c|c|}
\hline \multirow[t]{2}{*}{ Female sample $(\mathrm{N}=330)$} & Model 1 & & & Model 2 & & \\
\hline & B & SE & $\beta$ & B & SE & $\beta$ \\
\hline BPD & $.29 * * *$ & 0.07 & 0.23 & $.28 * * *$ & 0.06 & 0.22 \\
\hline DEPRESSIVE DISORDER & $.10^{*}$ & 0.04 & 0.12 & 0.07 & 0.04 & 0.09 \\
\hline CHILDHOOD ABUSE & & & & $.18^{* * *}$ & 0.05 & 0.21 \\
\hline ILLNESS/HOSPITALIZATION & & & & 0.09 & 0.06 & 0.08 \\
\hline $\mathrm{R}^{2}$ & \multicolumn{3}{|l|}{0.071} & \multicolumn{3}{|l|}{0.12} \\
\hline $\mathrm{F}$ & \multicolumn{3}{|l|}{$12.51^{* * *}$} & \multicolumn{3}{|l|}{$11.13^{* * *}$} \\
\hline \multirow[t]{2}{*}{ Male sample $(\mathrm{N}=184)$} & Model 1 & & & Model 2 & & \\
\hline & B & SE & $\beta$ & B & SE & $\beta$ \\
\hline BPD & $.39^{*}$ & 0.15 & 0.18 & $.36^{*}$ & 0.15 & 0.17 \\
\hline DEPRESSIVE DISORDER & 0.1 & 0.09 & 0.07 & 0.05 & 0.09 & 0.04 \\
\hline CHILDHOOD ABUSE & & & & $.20^{*}$ & 0.1 & 0.15 \\
\hline ILLNESS/HOSPITALIZATION & & & & 0.12 & 0.11 & 0.08 \\
\hline $\mathrm{R}^{2}$ & \multicolumn{3}{|l|}{0.04} & \multicolumn{3}{|l|}{0.07} \\
\hline $\mathrm{F}$ & \multicolumn{3}{|l|}{$3.74^{*}$} & \multicolumn{3}{|l|}{$3.49^{* *}$} \\
\hline${ }^{*} p<.05 ;{ }^{* *} p<.01 ;{ }^{* * *} p<.001$ & & & & & & \\
\hline
\end{tabular}

Depression instead does not show any significant correlation with drug abuse, when the diagnosis of borderline personality disorder is used as a predictor.

Introducing more other variables as predictors (child abuse, previous history of illness and/ or hospitalization), model 2 shows a significant percentage of variance in the dependent variable (females: R-frame $=.12, \mathrm{~F}(4)=11.13 ; \mathrm{p}<.001$; males: R-frame $=.072, \quad \mathrm{~F}(4)=3.49 ; \mathrm{p}=.009)$. A statistically significant effect of borderline personality disorder and early age abuse on drug abuse can be observed, excluding other independent variables considered $(\mathrm{p}<0.05)$. These associations are statistically significant both in male and female gender.

Among the results of this statistical analysis, it is noticeable the correlation between child abuse and higher hospital admissions (reported in $9.3 \%$ of the sample).

\section{Discussion}

The demographic profile of the sample shows a prevalence of female. This data support the hypothesis of several case reports [9] and reviews $[3,10]$ that FD occur mainly in women. However other studies published in literature show a clear prevalence in male gender. This illusory disagreement finds an explanation in Freyberger's words asserting that there is a prevalence of men in clinical trials for Munchausen Syndrome (MS), while the women are most common in the classic form of FD with a ratio of 3:1 [11].
People affected by FD tend to come to medical attention in young adult age. This outcome, in line with the results of several surveys $[3,12,13]$ supports the datum that FD patients arrive at medical attention in the young adult age.

A preponderance of patients with employment in healthcare emerged. According to a bio-psychosocial model and as confirmed by the literature, this finding, although not an absolute majority in patients of this study, suggests that a healthcare work can be a risk factor in the development of factitious disorder if associated to other stressful life events $[11,14]$.

A prevalence of married people emerged. Even though this result is in contrast to some researches in literature $[3,15]$, it can't be excluded that this data is partly conditioned by the impossibility to obtain this information from the whole sample examined. This aspect deserves a detailed study in the future.

The study shows a preponderance of comorbidity with personality disorders (specifically borderline personality disorder) and depressive disorders. This outcome is not surprising since the correlation between FD and personality disorders is frequently described in literature [16,17]. In the group with comorbidity, personality disorders and depressive disorders are the most represented. There are many studies published in the professional literature that support these connections $[18,19]$, but the relationship between these diagnosis is still unclear. 
All medical specialties may be interested in the management of factitious patients as evidenced by the clinical heterogeneity of the sample, but the study reveals a prevalence of psychiatry, emergency room and internal medicine departments. This finding moves away from previous scientific observations. Departments of psychiatry, emergency room and internal medicine are potentially at risk of meet with patients with FD. These data show that clinical presentation is considerably heterogeneous, but there are some specific clusters of psychiatric, trauma and neurological signs and symptoms. Despite there are some previous researches which disclose this aspect $[15,20]$, the psychiatric presentation has never been prevalent in previous studies [3,21]. This interesting observation emerged from this review suggests the possibility of underestimation of factitious patients who exhibit psychiatric symptoms and indicates the diagnostic and classification difficulties in patients with psychological signs or symptoms rather than physical ones.

The sample shows a prevalence of internal signs/symptoms and this could suggest that in FD there is a more marked internal dimension and that patients involve strategies such as falsification of clinical and personal history or pseudologia fantastica in order to keep it hidden. Inner pathologies are confined to a less obvious dimension, in which the act takes place in a hidden, internalized scene and where the subject becomes an executioner of idealistic objects represented in the somatic self, acting a sadomasochistic connection. The external and visible lesions are intrinsically exposed to the observer's gaze, and they are more closely related to the traditional concept of hysteria, in which the somatic self-action is loaded with a symbolic and communicative value $[22,23]$.

The review highlights the interesting relation between factitious disorder and recurrent surgery addiction. The American psychoanalyst Karl Menninger [24,25], dealing with polysurgery dependence or surgery addiction, considered FD as a suicidal equivalent.

Already Charcot, known for his studies on hysteria and hypnosis, identified passive operating mania in patients and complementary active operating mania in surgeons. Passive operating mania is an obsessive behavior associated with pain and disability which entails multiple request of surgical treatments in order to get relief $[23,24]$.
Various authors have tried to outline the psychological dynamic underlying the behavior of these patients. Concerning recurrent surgery, in 1972 Leon Chertok distinguished "polyopérés névrotiques", in which prevail relational and psychosexual development disorders, and "polyopérés psychopathiques", with characteristics of the so-called Munchausen Syndrome as the recourse to invasive diagnostic techniques and treatments [26,27].

The prevalence of abuse or neglect in childhood, substance abuse, conflicting interpersonal relationships, experience of illness and/or hospitalization in childhood and premature familiar bereavements discloses the hypothesis of the existence of a common denominator between FD and depressive disorders [2832]. Reich and Gottfried identified that the occurrence of many pathologies during childhood is one of the major factors for the development of a FD [33].

As already studied by different authors, these individuals respond to stressful life episodes by implementing pathological behavior as a coping mechanism [34].

Many authors believe that patients with FD are at high risk of suicide. The low percentage emerged, however, is supported by Yates's recent study [3], in which a $14.1 \%$ of suicidal behavior is observed.

$34.2 \%$ of patients of the sample refused or did not have the consultation. This fact undoubtedly reveals the difficulty of the doctors who rarely can establish a therapeutic alliance with patients. Subjects with FD with physical signs and symptoms unlikely accept to have a psychiatric interview, opposing to it or even discharge themselves from the hospital.

Among the factors leading to diagnosis of FD, the exclusion of other organic or psychiatric causes is the most represented. This is undoubtedly important both from a diagnostic point of view and because in patients with factitious disorders there may be physical or psychic comorbidity which are not diagnosed because of the nature of the disorder itself, which function as a confounding factor in the clinical presentation.

In scientific literature, there are some studies that highlight the importance of this aspect and hope that in future some guidelines will be drawn. That would help to diagnose factitious disorders starting from the unusual clinical presentation $[3,5,8]$. 
An atypical presentation is another key issue. These patients often use a scientific language without having any expertise in the field and they show a knowledge of the medical procedures and keep looking for invasive diagnostic examinations. Such behavior is also characterized by an ambivalent attitude towards the health workers by alternating a collaborative stance and an opposition to the therapeutic program, as well as the use of pseudologia fantastica. In the second case, there are repeated therapeutic failures that do not find an adequate physiological explanation as they are often a consequence of the patient's repeated pathological behavior.

The past use of health services has occurred in a significant percentage; the difficulty expressed by different authors in trying to reconstruct the clinical history of the patients affected by a factitious disorder is considered.

Evidence of factitious production has been observed in a small number of cases, and this highlights the difficulties in discovering the act itself, while avoiding to violate patient's privacy [11].

According to the results of this study, several authors have highlighted a frequent comorbidity between factitious disorders and depressive disorders [19], as well as a significant correlation between factitious disorder and borderline personality disorder [17].

Statistical analysis have highlighted significant correlations between abuses and neglect in childhood with depressive spectrum disorders and substance abuse but also between substance abuse, BPD and depressive disorder in the female sex. In male gender there are significant correlations between substance abuse and BPD as well as between abuse and neglect in childhood and substance abuse and past experience of illness or long-term hospitalization. Many studies in literature report a strong correlation between a history of physical and/or sexual abuse and the development of borderline personality disorder [35-41].

Substance abuse disorders are also associated with factitious disorders [42]. A statistically significant effect of BPD and abuses suffered in the childhood on substance abuse in both males and females emerged. In the female sex, depressive disorders have a significant effect on use of substances. In literature there are some case reports that confirm the results of this statistical analysis: in particular the relationship between drug abuse, depressive disorder and borderline personality disorder is supported $[43,44]$.

It is thus confirmed the previously discussed aspect, according to which important traumas in an individual's life, among which can be considered child abuse, could contribute to determine the psychic fragility typical of patients affected by a factitious disorder, laying the foundations of the pathological behavior itself.

The diagnostic criteria for DSM-5 factitious disorders were met in $88.7 \%$ of cases. The reason for the percentage of patients who do not meet the criteria $(11.3 \%)$ can be found in the reclassification that these conditions had in the modern edition of the manual: some patients who first met the criteria of previous editions are now most likely included in another diagnostic category. Medically unexplained symptoms are common and frequent in clinical practice and classifications have often limitations [45]. This is an intrinsic feature of manuals such as DSM that tend to designate rigid categories to avoid overlapping, but this inevitably conflicts with the clinical practice where flexibility is essential.

\section{Conclusions}

A systematic review on factitious disorders published in the professional literature was conducted.

With regard to the first endpoint, the survey of demographic profile of the sample has highlighted some important points for early diagnosis. The research also allows to deepen the psychopathological correlates of the disorder.

The third endpoint of this study is to evaluate the evolution of the classification of FD within the Diagnostic and Statistical Manual of Mental Disorders. With regard to this aim, the study showed that patients did not meet DSM-5 diagnostic criteria in the $11.3 \%$ of cases; this is due to the fact that the diagnostic reformulation has obviously caused the outplacement of some disease's diagnosis in other new additional sections of the DSM.

This study includes some limitations: firstly, the choice of case reports implies a bias of publication and selection: it may happen that some authors decide not to publish some cases as they are similar to other works in the literature or because they present already found or less severe manifestations. Another possible limitation is the fact that results of the study are based on case 
report or case series, as most of the literature on FD, and the design of the studies included is not RCTs.

In most cases the diagnosis of personality disorder has not been confirmed by the administration of structured interviews; this could be a possible limit of the analysis. Finally, it must be considered the impossibility to exclude that some case reports illustrate the same patient who comes to medical attention in different times and places since sometimes this kind of patients tend to go in various hospitals with a fake identity.

This study lays the foundations for future research that could confirm or deny some hypotheses: firstly, the prevalence of psychiatric presentations among FD patients and, secondly, the correlation between FD and depressive syndrome that outlines the possibility of detailed diagnostic and therapeutic study.

From the study of factitious disorders emerges the great difficulty of the physicians to obtain a complete and veritable history from these patients; this aspect inevitably involves confusion and delayed diagnosis, as well as it expose these patients to invasive and reiterated investigations.

The reality of general practice could suggest a solution to this problem because general practitioners could have a global clinical view on the patient. In this way, a proposal could be to raise the awareness in all physicians and to create a system that allows a dialogue among them in order to protect patients from useless procedures or diagnostic interventions. The goal is an early diagnosis and early psychiatric treatment.

It is also desirable to undertake a thorough research focusing specifically on the group of patients who don't fulfill the diagnostic criteria of the current DSM in order to understand clinical and psychopathological elements beyond the classification.

\section{Acknowledgments}

None

\section{Conflict of Interest}

The authors of this study declare that they have no conflict of interest.

\section{References}

1. American Psychiatric Association. DSM-5 Manuale Diagnostico e Statistico dei disturbi mentali. Milano: Raffaello Cortina Editore (2013).

2. Callegari C, Vender S, Ceccon F. Fondamenti di psichiatria: I disturbi fittizi. Milano: Raffaello Cortina Editore, 267-276 (2013).

3. Yates GP, Feldman MD. Factitious disorder: A systematic review of 455 cases in the professional literature. Gen Hosp Psychiatry 41(1), 20-28 (2016).

4. Feldman MD, Eisendrath SJ, Tyerman M. Psychiatric and behavioral correlates of factitious blindness. Compr Psychiatry 49(2), 159-162 (2008).

5. Steel R. Factitious disorder (Munchausen's syndrome). The Journal of the Royal College of Physicians of Edinburgh 39(4), 343-347 (2009).

6. Hoertel N, Lavaud P, Le Stratt Y, Gorwood P. Estimated cost of a factitious disorder with 6-years follow up. Psych Res 200(2-3), 1077107 (2012).

7. Bright R, Eisendrath S, Damon L. A case of factitious aplastic anemia. Int J Psychiatry Med 31(4), 433-41 (2001).

8. Bass C, Halligan P. Factitious disorders and malingering: Challenges for clinical assessment and management. Lancet 383(9926), 1422-1432 (2014).
9. Krahn LE, Li H, O'Connor MK. Patients Who Strive to Be III: Factitious Disorder With Physical Symptoms. Am J Psychiatry 160(6), 1163-1168 (2003).

10. Eastwood S, Bisson, Jl. Management of factitious disorders: a systematic review. Psychother Pychosom 77(4), 209-18 (2008).

11. Feldman MD, Eisendrath SJ. The spectrum of factitious disorders. Washington DC: American Psychiatric Press (1996).

12. Carney MW, Brown JP. Clinical features and motives among 42 artifactual illness patients. The Br J Med Psychol 56, 57-66 (1983).

13. Donegan, D, Hickey DP, Smith D. Hypoglycemia After Simultaneous PancreasKidney Transplant. Pancreas 41(6), 974-976 (2012).

14. Plassmann R. Münchhausen syndromes and factitious diseases. Psychother Psychosom 62(1-2), 7-26 (1994)

15. Kanaan R, Wessely SC(2010). Factitious disorders in neurology: an analysis of reported cases. Psychosomatics 51(1), 47-54.

16. Limosin F, Loze, JY, RouillonF. Clinical features and psychopathology of factitious disorders. Ann Med Interne 153(8), 499-502 (2002).

17. Nadelson T. The Munchausen spectrum: borderline character features. Gen Hosp Psychiatry 1(1), 11-7 (1979).

18. Gordon DK, Sansone RA. A relationship between factitious disorder and borderline personality disorder. Innovations in Clinical Neuroscience 10(11-12), 11-3 (2013).

19. Earle JR, Folks DG. Factitious disorder and coexisting depression: a report of successful psychiatric consultation and case management. Gen Hosp Psychiatry 8(6), 44850 (1986).

20. Bretz SW, Richards JR. Munchausen syndrome presenting acutely in the Emergency Department. J Emerg Med 18(4), 417-420 (2000).

21. Nicholson SD, Roberts GA. Patients who (need to) tell stories. Br J Hosp Med 51 (10), 546-9 (1990).

22. De Martis D, Vender S, Barale F. Atti del XXXVII Congresso Nazionale SIP. Progressi in Psichiatria. Standard Diagnostici ed Epidemiologia: I disturbi fittizi: aspetti clinici e psicodinamici. Roma: CIC Edizioni Internazionali (1989).

23. Callegari C. La maschera della finzione: I Modelli Interpretativi dei Disturbi Fittizi. Roma: II pensiero scientifico editore, 63-75 (1997).

24. Callegari C, Caperna S, Isella C, Bianchi L, Vender S, Poloni N. Multiple surgical interventions: diagnosis and psychopathology in recurrent operated patients. Minerva Psichiatrica 55, 215-23 (2014). 
25. Menninger AK. Polysurgery and polysurgic addiction. J Nerv Ment Dis 81(1), 93 (1934).

26. Callegari C, Caselli I, Bianchi L, Isella $C$, Vender S. Four clinical cases of recurrent surgery addiction (polyopérés): diagnostic classification in the DSM-IV-TR vs DSM-5. Neuropsychiatry 6(4), 178-184 (2016).

27. Callegari C, Bortolaso P, Vender S. A single case report of recurrent surgery for chronic back pain and its implications concerning a diagnosis of Münchausen syndrome. Functional Neurology 21(2), 103-108 (2006).

28. Norman RE, Byambaa M, De R, Butchart A, Scott J. The Long-Term Health Consequences of Child Physical Abuse, Emotional Abuse, and Neglect: A Systematic Review and Meta-Analysis. PLOS Medicine 9(11), 1-31 (2012).

29. Bovasso GB. Cannabis Abuse as a Risk Factor for Depressive Symptoms. Am J Psychiatry 158(12), 2033-2037 (2001).

30. Boden JM, Fergusson DM. Alcohol and depression. Addiction 106(5), 906-914 (2011).

31. Gao J, Li Y, CaiY, Chen J, Shen Y, Ni S, Wei Y, QiuY, Zhu X, Liu Y, Lu C, Chen C, NiuQ, Tang C, Yang Y, Wang Q, Cui W, Xia J, Liu T, Zhang J, Zhao B, GuoZ, Pan J, Chen H, Luo Y, Sun L, Xiao X, Chen Q, Zhao X, He F, LvL, GuoL, Liu L, Li H, Shi S, Flint J, Kendler
KS, Tao M. Perceived parenting and risk for major depression in Chinese women. Psychol Medicine 42(5), 921-30 (2012).

32. Geracioti TD, Van Dyke C, Mueller J, Merrin $E$. The onset of Munchausen's syndrome. Gen Hosp Psychiatry 9(6), 405-9 (1987).

33. Reich P, Gottfried LA. Factitious disorders in a teaching hospital. Ann Intern Med 99(2), 240-7 (1983).

34. Merrin EL, Van Dyke C, Cohen S, Tusel DJ. Dual factitious disorder. Gen Hosp Psychiatry 8(4), 246-50 (1986).

35. Gunderson JG, Sabo AN. The phenomenological and conceptual interface between borderline personality disorder and PTSD. Am J Psychiatry 150(1) 19-27 (1993).

36. Gunderson J, Zanarini M. American Psychiatric Press Review of Psychiatry: Pathogenesis of borderline personality disorder. Washington DC: American Psychiatric Press, 25-48 (1989).

37. Paris J, Zweig-Frank H. A critical review of the role of childhood sexual abuse in the etiology of borderline personality disorder. Can J Psychiatry 37(2), 125-8 (1992).

38. Stone M. Family Environment and Borderline Personality Disorder: Abuse and abusiveness in borderline personality disorder. Washington DC: American
Psychiatric Press, 131-148 (1990).

39. Terr LC. Childhood traumas: an outline and overview. Am J Psychiatry 148(1), 10-20 (1991).

40. Westen D, Ludolph P, Misle B, Ruffins $\mathrm{S}$, Block J. Physical and sexual abuse in adolescent girls with borderline personality disorder. Am J Orthopsychiatry 60(1), 55-66 (1990)

41. Van der Kolk BA, Perry JC, Herman JL. Childhood origins of self-destructive behavior. Am J Psychiatry 148(12), 16651671 (1991).

42. Mitchell D, Francis JP. A case of factitious disorder presenting as alcohol dependence. Substance Abuse 24(3), 187-189 (2003).

43. Good WV, Dubovsky SL. Pseudodementia masking substance abuse and depression. Psychosomatics 23(6), 652-657 (1982).

44. De Fontaine S, Van Geertruyden J, Preud'homme X, Goldschmidt D. Munchausen syndrome. Ann Plast Surg 46(2), 153-8 (2001)

45. Ferrari S, Poloni N, Diefenbacher A, Barbosa A, Cosci F. Modern psychopathologies or old diagnoses? From hysteria to somatic symptom disorders: searching for a common psychopathological ground. Journal of Psychopathology 21, 372-379 (2015). 